\title{
Características de la producción de objetos de aprendizaje por autores no especialistas en TIC
}

\author{
Irene Aguilar Juárez¹, Miguel A. León Chávez² \\ ${ }^{1}$ Centro Universitario \\ Universidad Autónoma del Estado de México \\ Av. Jardín Zumpango s/n Fracc. El Tejocote-Texcoco. Texcoco, Estado de México. C.P. 56259 \\ ireneico@gmail.com \\ ${ }^{2}$ Facultad de Ciencias de la Computación \\ Benemérita Universidad Autónoma de Puebla \\ 14 sur y Av. San Claudio, CU. Puebla. C.P. 72570 \\ maleon63@gmail.com
}

Fecha de recepción: 4 septiembre 2014

Fecha de aceptación: 21 de octubre 2014

\section{Resumen}

Con el objetivo de caracterizar el proceso de producción de objetos de aprendizaje por autores no especialistas en tecnologías de la información y la comunicación se realizó una encuesta entre los docentes del Centro Universitario de la Universidad Autónoma del Estado de México, campus Texcoco. Este artículo presenta los resultados de la encuesta y los analiza.

\section{Palabras Clave}

Objetos de Aprendizaje, Aprendizaje Electrónico.

\section{Summary.}

In order to characterize the production process of learning objects for nonspecialists authors in information and communication technologies a questionnaire was applied to the teachers of the University Center of the Autonomous University of the State of Mexico, campus Texcoco. This paper presents the results of the survey and analyzes them.

\section{Keywords}

Learning Objects, e-learning. 


\section{Introducción}

El desarrollo de las tecnologías de la información y la comunicación (TIC) han impactado todos los aspectos de la vida humana entre ellos la educación, en particular la superior, lo que ha permitido generar materiales educativos para todas las áreas del conocimiento. En consecuencia los principios pedagógicos también se han modifican pues las TIC hacen posible tener una comunicación asíncrona y ubicua entre el alumno, el profesor y el conocimiento. En opinión de [1] "se rompe con el monopolio del profesor como fuente principal del conocimiento; aumentan la autonomía del alumnado; transforman sustantivamente los modos, formas y tiempos de interacción entre docentes y alumnado; Internet permite y favorece la colaboración entre docentes y estudiantes más allá de los límites físicos y académicos de la institución a la cual pertenecen".

Para Vigotsky citado en [2] los instrumentos psicológicos son todos los sistemas semióticos, prácticas, procedimientos y técnicas conceptuales de los medios de comunicación, operaciones y estructuras de carácter intelectual que se dan en todas las adquisiciones de la cultura. Son una extensión de las habilidades del ser humano cuyo uso influye en el desarrollo del individuo. Los materiales educativos en general cumplen con las propiedades de los instrumentos psicológicos; están formados por elementos simbólicos, textuales y sobre todo son un producto cultural. Su valor radica en permitir el desarrollo de procesos cognitivos superiores. Santacruz-Rodríguez en [3] explica que "los instrumentos presentan una fuerte influencia en la construcción del saber y en sus modos de construcción".

De forma particular los medios audiovisuales presentan varias ventajas para la construcción del conocimiento, en opinión de [4] los recursos audiovisuales "permiten presentar mensajes al sentido más altamente desarrollado que es la visión, ayudan a concentrar el interés y la atención de los alumnos, pueden relacionar principios abstractos con objetos concretos, pueden ilustrar claramente las interrelaciones entre objetos o procesos, pueden comunicar mensajes difíciles o imposibles de expresar con palabras solamente y pueden prepararse en forma realista como en forma abstracta".

En este contexto los materiales educativos se convierten en los principales mediadores mediante los cuales el estudiante construye su aprendizaje y por otro lado el papel del docente se transforma pues su rol en el proceso de enseñanzaaprendizaje cambia. En [5] se señala la importancia de que el docente sea capacitado en el conocimiento de las características de los entornos tecnológicos, pues de otra manera el docente no puede aprovechar la potencialidad didáctica que ofrecen las TIC.

La evolución tecnológica no solo ha incidido en las prestaciones y bondades de los medios de comunicación disponibles en la relación docente-alumno, también han 
modificado la forma de producir, gestionar y conceptualizar a los materiales educativos, un ejemplo de esta situación son los Objetos de Aprendizaje (OA).

Un OA ha sido definido [6] como cualquier recurso digital que se puede utilizar como apoyo para el aprendizaje, tal como archivos de texto, imágenes, animaciones, video, audio, simuladores, tutoriales, páginas web, blogs, etc. Note que de acuerdo con esta definición cualquier material educativo digital es un $\mathrm{OA}$ y es la que se emplea en este artículo.

Sin embargo, autores especialistas en TIC han incorporado otras características a los OA, por ejemplo en [7] se propone desarrollar y evaluar los OA que contengan el nivel cognitivo de la taxonomía de Bloom, es decir el OA debe facilitar al alumno adquirir conceptos, comprender fundamentos teóricos, analizar, sintetizar, aplicar y evaluar lo aprendido; por lo que los autores proponen los siguientes componentes de un OA: contenido temático, diseño instruccional, diseño estético y metadato estandarizado.

Otros autores [8] han visto a los OA como productos y como tales deben ser sometidos a procesos de producción donde el objetivo es reducir el costo de su elaboración para aumentar la ganancia; de aquí que el OA además de tener un objetivo de aprendizaje se le añadan características deseables tales como: etiquetado con metadatos (información mínima para administrar, localizar y evaluar el OA), reusable, interoperable, accesible, disponible, portable, compartible, durable, etc.

El proceso de producción de OA ha sido comparado con una línea de ensamble [8], como la de los automóviles o computadoras, donde la revolución industrial y sus procesos subyacentes permiten acceso masivo a los bienes de consumo moderno y altos estándares de vida. El reto, de acuerdo a los autores, es entrenar a los autores (docentes) para que adopten nuevas formas de trabajo - una evolución de la aproximación artesanal a una aproximación en línea de ensamble más estandarizada.

El papel de los materiales educativos digitales, tal como los OA, en su función de instrumentos psicológicos es fundamental para lograr el aprendizaje de los alumnos por esta razón es necesario conocer cómo se usan y generan por autores no especializados en TIC, pues conociendo las propiedades de este proceso se pueden diseñar estrategias que faciliten el uso y la producción, optimicen y mejoren los instrumentos psicológicos.

Con el objetivo de caracterizar el proceso de producción de OA por autores no especialistas en TIC, este artículo presenta los resultados de una encuesta realizada a los docentes del Centro Universitario de la Universidad Autónoma del Estado de México (CU UAEM), campus Texcoco. El resto del artículo está organizado de la siguiente manera: la sección 2 presenta las características de los docentes del CU UAEM campus Texcoco, la sección 3 presenta la encuesta y los resultados, en la sección 4 se analizan los resultados de la encuesta, finalmente se resumen las conclusiones y trabajo a futuro. 


\section{Docentes del CU UAEM}

El Centro Universitario de la Universidad Autónoma del Estado de México (CU UAEM) campus Texcoco se ubica en la Región Oriente del Estado de México, brinda servicios educativos a los municipios de Texcoco, Nezahualcóyotl, Chiconcuac, Chicoloapan, Chimalhuacán, Papalotla, Ecatepec, Los Reyes la Paz, Tepexpan, Acolman, Ixtapaluca, Chalco y Teotihuacán, así como a la delegación Iztapalapa del Distrito Federal.

En este centro se ofertan los siguientes programas de Licenciatura en modalidad presencial: Contaduría, Administración, Derecho, Economía, Turismo, Ciencias Políticas y Administración Pública, Informática Administrativa, Lenguas Inglesas e Ingeniería en Computación. También se oferta los siguientes programas de Posgrado presenciales: Maestría en Gobierno y Asuntos Públicos, Ciencias de la Computación y Procesos Jurídicos o Penales.

De acuerdo con la agenda estadística del año 2011 [9] el CU UAEM cuenta con 170 docentes que atienden a 2,464 alumnos inscritos. De los 170 docentes, 17 (10\%) son profesores de tiempo completo (13 hombres y 4 mujeres), 1 profesora es de medio tiempo y 152 (89.41\%) son profesores de asignatura (86 hombres y 66 mujeres), es decir su contratación es por horas clase. Por norma institucional, los docentes no son contratados por más de 18 horas/clase a la semana, razón por la cual los docentes ejercen su profesión en distintas instituciones o empresas ajenas a la Universidad. La Universidad oferta capacitación pedagógica y disciplinar sin costo a los docentes cada periodo inter semestral.

De los 170 docentes adscritos al Centro Universitario, 22 tienen una licenciatura o maestría en Computación o Informática; de los 170, 10 de ellos tienen licenciatura o maestría en Educación por lo que se estima que el $18.8 \%$ podría cubrir el perfil necesario para desarrollar material educativo digital; el $81.1 \%$ tiene una formación distinta a la Informática, Computación o Educación por lo que se les considera no especialistas en TIC. La diversidad de perfiles académicos en la planta docente y la cobertura del Centro Universitario permiten realizar estudios educativos sobre docentes y alumnos de formación heterogénea.

\section{Encuesta y resultados}

Para aplicar la encuesta se generó un cuestionario en línea en Google Docs y se invito, por medio de un correo electrónico, a los docentes del CU UAEM a responderla en un plazo de 14 días.

De los 170 docentes se recuperaron 135 direcciones de correo electrónico, 27 resultaron erróneos por error de escritura o captura, de los 108 correos válidos se obtuvieron 56 respuestas, lo que representa el $32.9 \%$ del total de los docentes y el $51.85 \%$ de los docentes que respondieron la encuesta, en el cuestionario no se les 
solicito que indicaran su tipo de contratación, es decir si es profesor de tiempo completo, medio tiempo u hora clase.

\subsection{Cuestionario}

Con el cuestionario se pretende descubrir la frecuencia entre los docentes de generar o adaptar materiales educativos, el tiempo dedicado a la generación del material, las fuentes de información que usan los docentes, la frecuencia de uso de recursos multimedia, libros o sitios web especializados, el tipo de instrumentos de evaluación que aplican y el tipo de software que usan. Así como la forma en que se organizan los docentes para producir su material.

Para determinar la preferencia de los docentes sobre la obtención de sus recursos educativos, en este cuestionario se adaptaron las opciones que se usan en [10] dado que las modalidades educativas del CU UAEM son presenciales y no a distancia. En [10] se señala que al momento de requerir material educativos "básicamente, se plantean cuatro posibilidades: (1) emplear materiales no diseñados para educación a distancia (EaD); (2) utilizar materiales diseñados para EaD por otras instituciones; (3) adaptar materiales no diseñados para EaD; y (4) elaborar nuestros propios materiales". La adaptación consistió en limitar a 3 las opciones, siendo éstas: (1) produzco mis propios materiales, (2) selecciono materiales ya existentes y (3) adapto materiales ya existentes.

Para determinar el dominio del docente sobre el software de edición se adaptó el criterio "ICT Skills Index" citado en [11] que se basa en tres niveles de dominio, concordantes con la posición del sujeto frente a las siguientes afirmaciones:

1. "Puedo hacer ese tipo de tareas completamente solo" (se usaron las opciones: "lo sé usar", "lo uso muy frecuentemente", "lo uso frecuentemente", "según el caso").

2. "Necesitaría alguna ayuda para realizar ese tipo de tareas "(se usaron la opciones: "lo uso poco", pues el poco uso es señal de poco dominio en la herramienta).

3. "Jamás en mi vida he realizado ese tipo de tareas" (se usaron las opciones: "no lo sé usar" o "nunca lo uso").

Al igual que en el estudio [11] se cuestionó sobre el uso de las siguientes aplicaciones de software:

- diseño Web

- manejador de presentaciones,

- programas para elaborar gráficos,

- hojas de cálculo,

- procesadores de texto. 
A estas aplicaciones de software se añadió el uso de software para desarrollar animaciones, el uso de simulaciones y el manejo de otro tipo de lenguajes de programación, sin embargo no se cuestionó por el uso de chat y correo electrónico.

El cuestionario se formó con preguntas de tipo nominal para caracterizar la producción de OA por los docentes; note que en la encuesta se uso el término material educativo en lugar de OA para ofrecer mayor claridad a los encuestados.

Las preguntas son las siguientes:

Instrucciones: Selecciona la opción que más se acerque a tu situación o preferencia

1. Identifica tu práctica más común para usar material educativo

a) Produzco mis propios materiales educativos

b) Selecciono materiales ya existentes

c) Adapto materiales ya existentes

2. ¿Cuánto tiempo inviertes en la producción de materiales educativos?

a) Menos de $2 \mathrm{hrs}$. a la semana

b) De 2 a 5 hrs. a la semana

c) De 5 a $10 \mathrm{hrs}$. a la semana

d) Más de $10 \mathrm{hrs}$. a la semana

3. Indica la frecuencia de uso de las siguientes fuentes de información para tus clases

Opciones: 1 No lo uso. 2 Poco uso. 3 Frecuente. 4 Muy frecuente.

Artículos Científicos

Libros impresos

Sitios Web especializados

Casos de estudio

Experiencia personal

4. Indica la frecuencia de uso que haces de los siguientes materiales educativos

Opciones: 1 No lo uso. 2 Poco uso. 3 Frecuente. 4 Muy frecuente.

Diapositivas

Apuntes escritos

Manuales de Prácticas

Monografías

Libros de Texto

Software educativo On-Line (simuladores, sitios web, plataformas educativas)

Software educativo Off-Line (CD-ROM, aplicaciones en PC, USB)

Archivos de Audio

Videos o películas

Obras de teatro, museos, visitas guiadas

5. Indica la frecuencia de uso de los siguientes instrumentos de evaluación

Opciones: 1 No lo uso. 2 Poco uso. 3 Frecuente. 4 Muy frecuente.

Exámenes abiertos con preguntas abiertas 
Cuestionarios de opción múltiple

Listas de cotejo

Elaboración de ensayos o trabajos de investigación documental

Elaboración de proyectos

Reportes de prácticas

Elaboración de apuntes

6. Indica la frecuencia de uso de las siguientes aplicaciones o recursos educativos

Opciones: 1 No lo sé usar. 2 Lo sé usar pero lo hago poco. 3 Lo uso algunas veces. 4 Lo uso con frecuencia. 5 Lo uso siempre.

Editores de texto (Word)

Presentaciones (power point)

Editores de imágenes

Editores de sonido

Editores de audio

Editores de video

Editores de páginas web

Desarrollo de aplicaciones interactivas en flash

Desarrollo de aplicaciones con otros lenguajes

Simuladores especializados

Uso de blogs en Internet

Uso de wikis

Uso de plataformas educativas (seduca, moodle, sakai, blackbloard)

7. ¿Produces material educativo en equipo?

a) $\mathrm{Si}$

b) No

8. En caso de producir material educativo en equipo contesta las siguientes preguntas

¿De cuantas personas se forma tu equipo de trabajo?

a) De 2 a 4 personas

b) De 5 a 7 personas

c) Igual o más de 8

¿Existe un rol específico para cada miembro del equipo?

a) $\mathrm{Si}$

b) No

¿Usan alguna metodología para producir su material educativo?

a) $\mathrm{Si}$

b) No

De ser afirmativa la respuesta anterior ¿Cuál? 


\subsection{Resultados}

La figura 1 muestra las respuestas a la pregunta 1, note que casi tres cuartas partes de los docentes (73\%) están involucrados en la producción de material educativo mientras que una cuarta parte selecciona y adapta el ya existente.

El reuso de OA, en general, es una de sus características deseables, sin embargo el reuso debe estar basado en la evaluación de su calidad porque se asume que un OA con calidad es más eficaz en el proceso de aprendizaje, pero dada la diversidad de recursos educativos digitales existentes en los repositorios (archivos de texto, imágenes, animaciones, audio, simuladores, tutoriales, páginas web, etc.) no ha permitido definir un conjunto de características de calidad a cuantificar que sea válido para todos los OA.

Por ejemplo: en [12] se propuso contar el número de palabras para medir la calidad de los artículos en Wikipedia; en [13] se propuso evaluar los OA basados en página web con las siguientes clases: ligas, texto, gráficas y arquitectura del sitio. Las cuales tienen las siguientes métricas: número de ligas, número de ligas únicas, número de ligas internas, número de ligas internas únicas, número de ligas externas, número de ligas externas únicas, tamaño de la página (en bytes), número de imágenes, tamaño total de las imágenes (en bytes), número de scripts, número de palabras, número de palabras que son ligas, número de applets, y número promedio de cada una de las métricas anteriores.

Como se puede apreciar estas propuestas no miden la construcción del conocimiento que realizan los estudiantes por lo que es necesario definir características a cuantificar de los OA que guíen su producción, uso y adaptación por parte de los docentes.

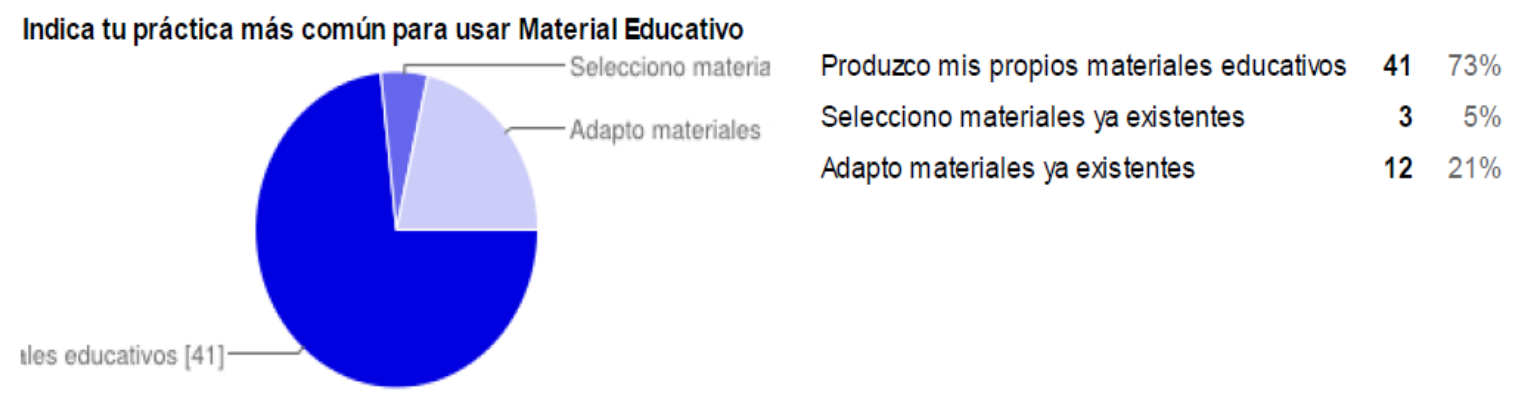

Fig. 1. Práctica más común para usar material educativo entre los docentes del CU UAEM.

Las respuestas a la pregunta 2 se muestran en la figura 2 donde se puede observar que más de la mitad de los docentes invierte de 2 a 5 hrs. a la semana; si consideramos que un profesor de tiempo completo labora $40 \mathrm{hrs}$. a la semana y tiene una carga académica de $18 \mathrm{hrs}$. a la semana frente a grupo, los docentes dedican $45 \%$ de su tiempo a la docencia y entre el $5 \%$ y $12.5 \%$ de su tiempo a desarrollar material educativo. El $30 \%$ de los docentes emplea de 5 a $10 \mathrm{hrs}$. a la semana por lo 
que destina de 12.5 a $25 \%$ de su tiempo. Note que este tiempo va en detrimento de otras actividades tales como investigación y vinculación.

En el caso de los profesores hora clase, con un máximo de $18 \mathrm{hrs}$. a la semana frente a grupo, esto representa que los docentes invierten entre el $11.1 \%$ y el $27.7 \%$ de tiempo extra; y entre el $27.7 \%$ y $55.5 \%$ de tiempo extra, respectivamente, para producir su material educativo en detrimento de su actividad profesional en otras instituciones.

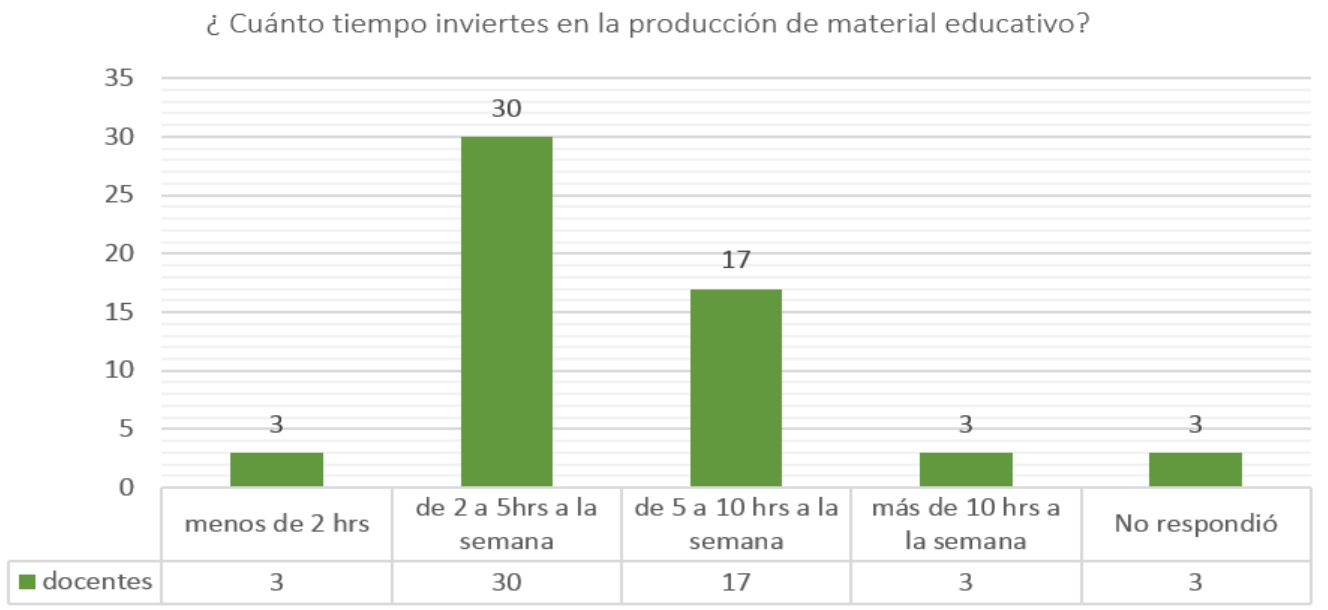

Fig. 2. Tiempo invertido por los docentes del CU UAEM en la producción de materiales educativos.

La figura 3 muestra la frecuencia de uso de las fuentes de información. Se puede notar que el $87.5 \%$ usa frecuentemente o muy frecuentemente los libros impresos; el $91.0 \%$ usa frecuentemente o muy frecuente su experiencia personal; el $51.7 \%$ usa poco a los artículos científicos y el $26.7 \%$ no usa o usa poco los casos de uso.

Es interesante observar que la principal fuente de información de los docentes es el libro impreso sin que ellos actualicen la información con aquella que se publica en los artículos científicos. Note que algunas áreas de conocimiento, como las ingenierías y tecnologías, se han desarrollado vertiginosamente en los últimos años por lo que los libros dejan de ser vigentes en poco tiempo lo que pude provocar que los docentes transmitan información desactualizada.

Por otro lado, aunque no tenemos información de la experiencia profesional de los docentes en otras instituciones públicas o privadas, se observa el uso mayoritario de la experiencia personal de los docentes como fuente de información lo que no se refleja en el mismo porcentaje que los casos de estudio lo que hace suponer que la experiencia personal hace referencia únicamente a la docencia. 


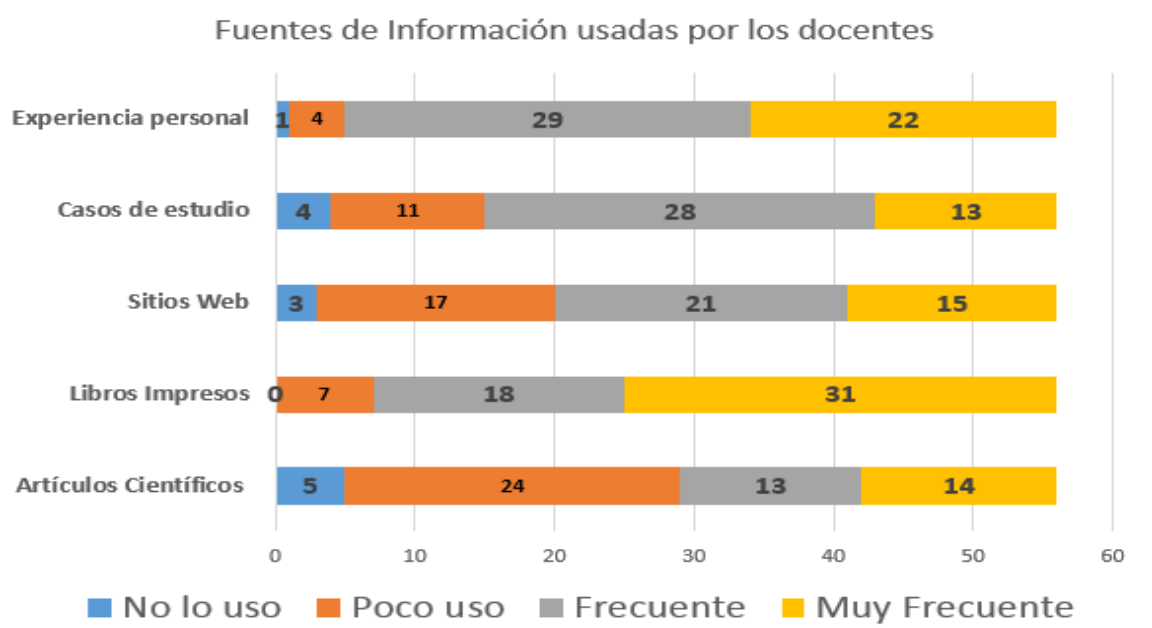

Fig. 3. Frecuencia de uso de las fuentes de información por los docentes del CU UAEM.

La figura 4 presenta las respuestas a la pregunta 4 , donde se puede observar que el $83.9 \%$ de los docentes usa muy frecuentemente los libros de texto; el $62.5 \%$ usa frecuentemente los apuntes impresos; el $80 \%$ usa poco las monografías y el $92 \%$ no usa o usa poco las obras de teatro, las visitas guiadas o los museos.

Note que aunque los docentes usan muy frecuentemente los libros de texto no se refleja en la misma proporción que las diapositivas y apuntes, es decir los docentes no están usando los recursos educativos que acompañan a los libros modernos y que incluyen página web, diapositivas, figuras, tablas, hoja de errores, ejercicios, prácticas, lista de correo electrónico y ligas de interés.

Además se observa un porcentaje muy bajo en el uso de manuales de prácticas lo que hace suponer una formación únicamente teórica; como trabajo a futuro se propone documentar el número de laboratorios por carrera y las prácticas que realizan los estudiantes, si es el caso.

Note además el porcentaje tan bajo en el uso de software educativo en línea y fuera de línea; hoy en día en la red Internet existe gran variedad de software educativo libre en el Internet por lo que es necesario capacitar a los docentes en su búsqueda y uso. 


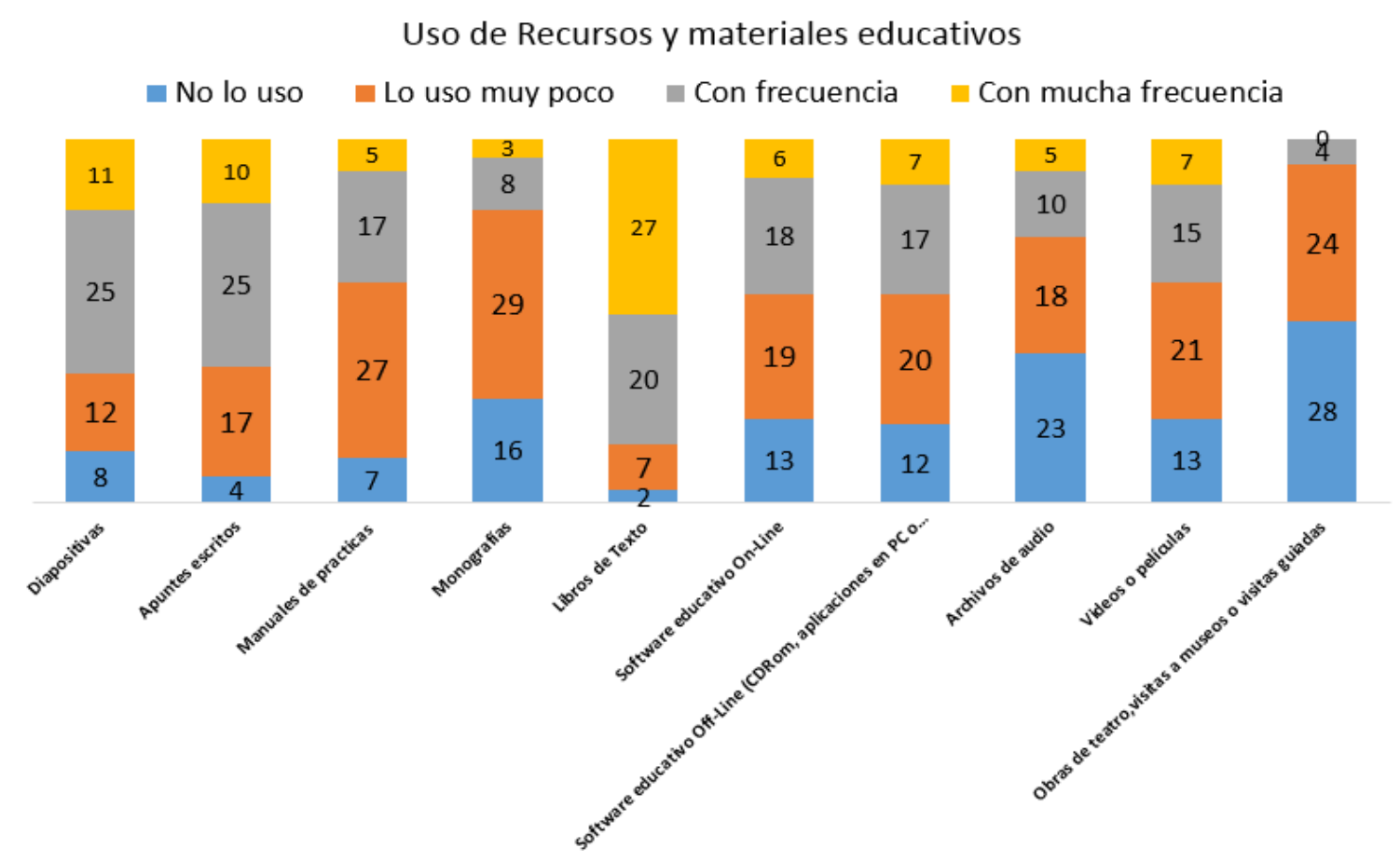

Fig. 4. Frecuencia de uso de los materiales educativos por los docentes del CU UAEM.

La frecuencia de uso de instrumentos de evaluación se presenta en la Fig. 5, se puede notar que el $28.57 \%$ usa muy frecuentemente los ensayos, trabajos de investigación y la elaboración de proyectos; el $55.35 \%$ usa frecuentemente los cuestionarios de opción múltiple; el $35.71 \%$ usa poco los exámenes escritos; y el $19.64 \%$ no usa las listas de cotejo.

Note que los docentes prefieren evaluar a los alumnos por elaboración de ensayos, documentación y proyectos complementado con exámenes escritos o de opción múltiple. Sin embargo, 14 docentes incluyen reportes de prácticas resultado que es contradictorio con el resultado de la pregunta anterior donde sólo 5 docentes declararon usar manuales de prácticas, precisar la formación práctica y experimental de los estudiantes es importante en un trabajo a futuro. 


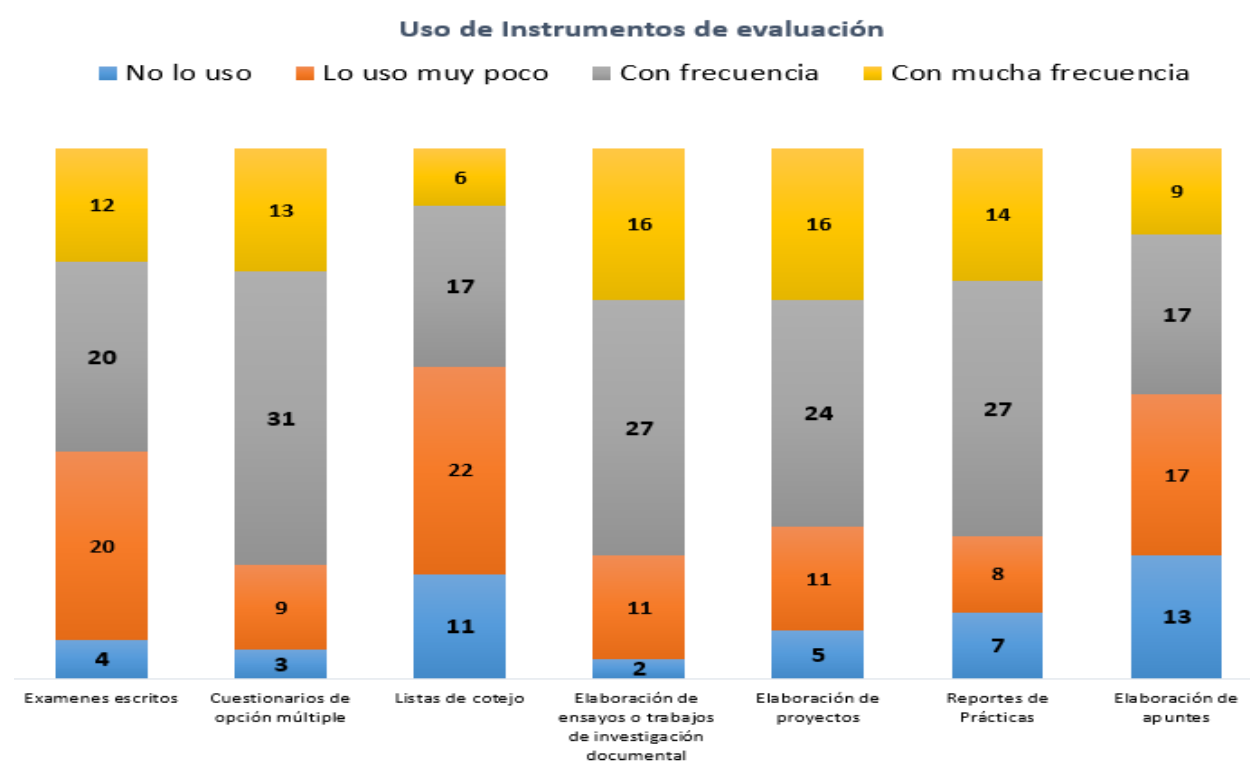

Fig. 5. Frecuencia de uso de los instrumentos de evaluación por los docentes del CU UAEM.

La Fig. 6 presenta la frecuencia de uso de software para producir o gestionar materiales educativos por los docentes del CU UAEM, se puede observar que el $73 \%$ usa siempre o con mucha frecuencia al procesador de texto word; el $69 \%$ usa con frecuencia o siempre las presentaciones power point; el $48.2 \%$ usa algunas veces los editores de imágenes; el $30.3 \%$ sabe usar pero usa poco los blogs en Internet; y el $50 \%$ no sabe desarrollar aplicaciones con otros lenguajes de programación. Además se observa que los docentes no saben usar las siguientes herramientas: editores de sonido ni de video (92\% y 94\%), aplicaciones interactivas en flash ni simuladores (71\%), blogs en Internet (25\%), wikis (39\%), ni las plataformas educativas (41\%). 
Uso de software para desarrollar material didáctico

No lo sé usar Sé usarlo pero no lo hago con frecuencia — Lo uso algunas veces — Lo uso con mucha frecuencia — Lo uso siempre

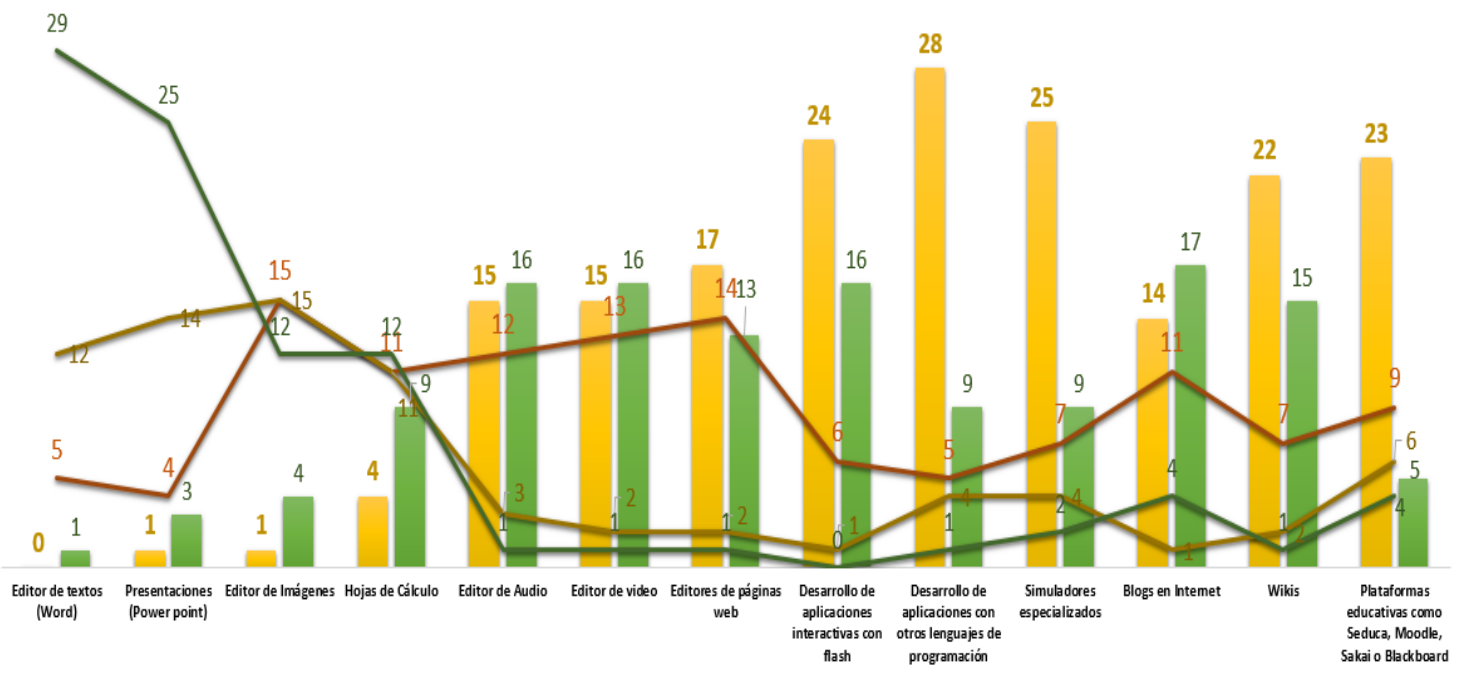

Fig. 6. Frecuencia de uso de las siguientes aplicaciones o recursos educativos por los docentes del CU UAEM.

Con respecto a la pregunta ¿Produces material educativo en equipo? El 62.5\% de los docentes respondió negativamente, como se muestra en la Fig. 7. Las respuestas a la pregunta 8 se muestran en las Fig. 7 y 8 , donde se puede notar que del $37.5 \%$ de los docentes aceptaron producir material educativo en equipo. De los cuales el $57 \%$ manifestó hacerlo en equipo de 2 a 4 personas; $24 \%$ de 5 a 7 y sólo el $5 \%$ lo hace con más de 8 personas.

Además, el $55.35 \%$ manifiesta elaborar el material educativo sin definir un rol entre ellos y finalmente el $58.92 \%$ no usa una metodología en el desarrollo del material educativo. 


\section{Aspectos sobre la producción de materiales educativos}

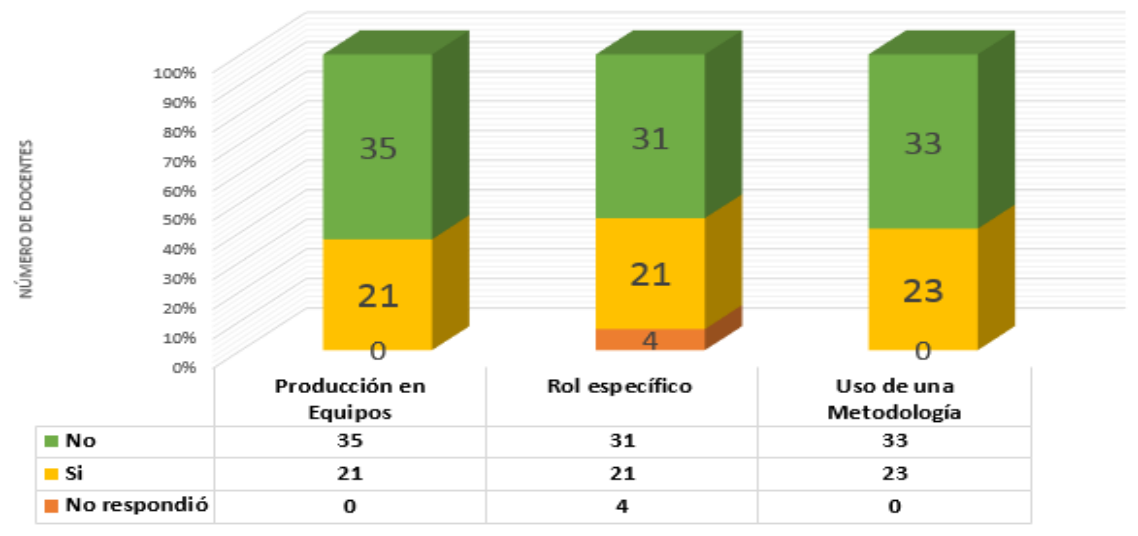

Fig. 7. Respuestas a la pregunta 7 ¿Produces material educativo en equipo?

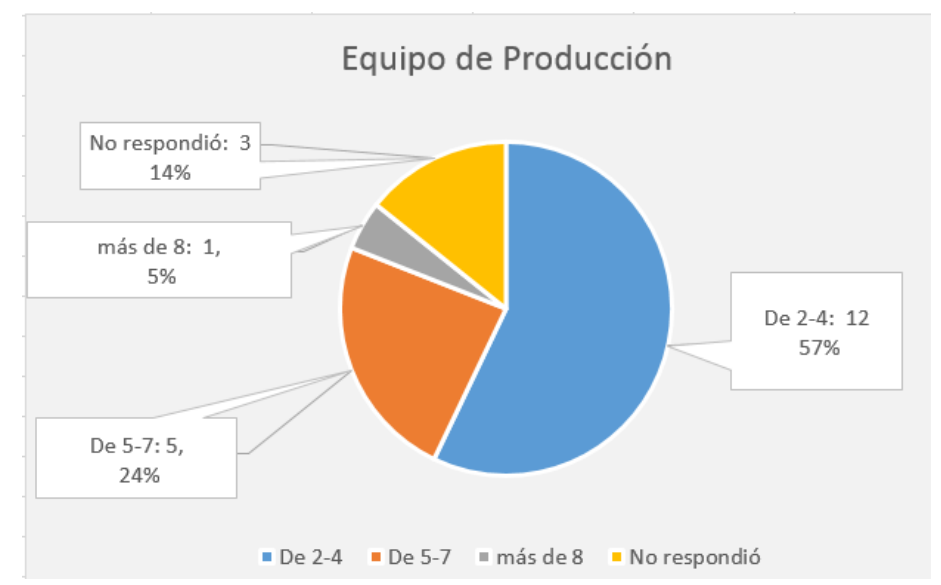

Fig. 8. Respuestas a la pregunta 8. ¿De cuántas personas se forma tu equipo de trabajo?

\section{Análisis de los resultados}

Los resultados de la encuestan permiten observar que entre los docentes del Centro Universitario es muy común que dediquen su tiempo a la producción y adaptación de materiales educativos. A esta tarea el 53.57\% de ellos dedican entre 2 y 5 horas a la semana. Para un profesor de tiempo completo representa el $12.5 \%$ de su tiempo y para un profesor hora clase hasta el $27 \%$ de tiempo extra a las 18 horas clase frente a grupo.

Las principales fuentes de información para los docentes son el libro y los textos académicos impresos como los apuntes y los artículos científicos, después le sigue la experiencia personal y el análisis de casos de estudio. Respecto a los instrumentos de evaluación los resultados muestran que más de la mitad de los docentes usa los 
cuestionarios de opción múltiple, los reportes de práctica y los trabajos de investigación.

Sobre el software que usan los docentes para adaptar o producir sus materiales educativos los resultados muestran que alrededor del $70 \%$ usan el software de ofimática para generar sus materiales, estos datos son más bajos que los reportados en [3], en los que se reporta que el $42 \%$ de los docentes evaluados en España se manifiesta con competencias "Altas" sobre el manejo de ofimática y navegación web y el $58 \%$ se considera "Muy alto" en la misma habilidad, sumadas estas cantidades se obtiene que el $90 \%$ de los docentes cuestionados se consideran con habilidades altas o muy altas.

Aunque hay que observar que los porcentajes de este estudio se acercan a los resultados respecto al uso de aplicaciones específicas como editores de presentaciones o de textos [3], en los que señala que el $79 \%$ de los docentes investigados usan editores de texto, el $78 \%$ son creadores de presentaciones visuales y el $73 \%$ usan software específico de su ámbito de trabajo. Además es importante señalar que en el presente estudio se detecta que aunque algunos docentes manifestaron conocer los editores de páginas web, blogs y editores de video no los usan en su práctica docente. Cabe preguntarse la razón por la cual los docentes no aplican esos conocimientos.

También se detecta que los docentes hacen poco uso de las plataformas educativas de la institución pues aunque la Universidad Autónoma del Estado de México ha desarrollado la plataforma Seduca y ofrece servicios a comunidades virtuales mediante Moodle los datos aquí observados indican que sólo el $17 \%$ de los docentes reporta usarlas frecuentemente o muy frecuentemente, contra el $82 \%$ que manifiesta no usarlas o usarlas poco. Esta situación debe mejorarse pues en otros trabajos [14] se reporta que la mayor parte de los docentes conocen (88\%) y usan (84\%) la plataforma propia de su universidad y que el $71 \%$ responde favorablemente cuando se les pregunta si suelen publicar su material didáctico a través de Internet.

Sobre los equipos de producción la mayoría de ellos (83\%) señalan que su equipo de desarrollo de materiales educativos no excede a 4 personas, la gran minoría $(1.7 \%)$ trabaja en grupos de más de 8 elementos y más de la mitad manifiestan no usar una metodología para desarrollar sus materiales. Estos datos también coinciden con la problemática identificada en [1] donde se enfatiza que existen "dificultades que enfrentan muchos docentes a la hora de integrar equipos para desarrollar software adaptado a sus programas educativos, sobre todo porque en la revisión de literatura relacionada con esta problemática, se evidenció que existe muy poca información publicada en lenguaje de fácil acceso para el docente no especializado y mucho menos que considere la necesidad de integrar los aspectos pedagógicos a los desarrollos de software efectuados desde la programación, para las prácticas educativas". En consecuencia se observa que aunque la mayoría de ellos desarrolla sus materiales educativos y dedica al menos dos horas a la semana a preparar su 
material, los docentes están realizando esta tarea con dificultades técnicas y con falta de información o metodologías.

\section{Conclusiones y trabajos futuros}

Este artículo presenta los resultados de una encuesta realizada a los docentes del Centro Universitario de la Universidad Autónoma del Estado de México (CU UAEM), campus Texcoco; los resultados permiten caracterizar el proceso de producción de material educativo digital por autores no especialistas en tecnologías de la información y la comunicación.

De los resultados se puede observar que la producción de materiales educativos es una actividad muy frecuente de los docentes y la realizan mayoritariamente en forma individual (35\%) y sin usar una metodología (33\%). De los profesores que aceptan elaborar su material educativo en equipos lo hacen en grupos pequeños de producción (57\%), usando roles (21\%) y una metodología (23\%). Por lo que existe una necesidad de definir una metodología de producción de materiales educativos digitales para grupos pequeños de autores no especialistas en TIC; en este sentido los autores han revisado el estado del campo del arte y han propuesto una metodología publicada en [15].

Los resultados confirman la necesidad de capacitar al docente en la aplicación de nuevas formas de interacción con el alumno pues en opinión de [5] "el perfeccionamiento profesional del docente sólo tendrá un impacto si se centra en cambios específicos del comportamiento del docente en clase y, en particular, si ese perfeccionamiento es permanente y se armoniza con otros cambios en el sistema educativo".

Por otro lado, es necesario promover y difundir el uso de las plataformas educativas institucionales y las herramientas de autor que permitan usar eficientemente los recursos humanos y materiales que actualmente se dedican a la producción de materiales educativos y así aumentar su producción y el aprovechamiento de estos recursos.

A futuro es importante también identificar con mayor detalle la forma de uso que los docentes hacen de las TIC, ya que publicaciones recientes [16] han reconocido que los docentes pueden usar estos recursos de varias formas:

1. Como medio de autoestudio o presentación

2. Como herramienta de trabajo

3. Como herramienta de evaluación

4. Como extensión de su comunicación

5. Como relleno o escenario

Tener esta información permitirá planificar programas adecuados de capacitación a los docentes de la Zona Oriente del Estado de México con la finalidad de lograr niveles de uso semejantes a los alcanzados en países desarrollados como Estados 
Unidos y la Unión Europea que tienen claramente definidas las características de las competencias docentes en el uso de las TIC y están estableciendo estándares para evaluar el desempeño y las habilidades del docente [17].

Agradecimientos

Los autores agradecen a las autoridades del Centro Universitario UAEM campus Texcoco por facilitar el desarrollo de esta encuesta al proporcionar el contacto con los docentes y por promover la respuesta del cuestionario entre los docentes del campus.

\section{Referencias}

1. Inciarte R. M.: Competencias docentes ante la virtualidad de la educación superior, Telematique, Vol. 7, No. 2, pp. 19-38, 2008. Recuperado en agosto 2014, disponible en http://www.publicaciones.urbe.edu/index.php/telematique/article/view/843/2067

2. Ivic, I.: Lev Semionovich Vygotsky (1896-1934). Perspectivas: revista trimestral de educación comparada. Vol. XXIV No. 3-4. pp. 773-799, 1994. Disponible en http://www.ibe.unesco.org/publications/ThinkersPdf/vygotskys.PDF

3. Santacruz, R. M.: La gestión del profesor desde la prespectiva de la mediación instrumental. En $10^{\circ}$ Encuentro Colombiano de Matemática Educativa, 2009. Disponible en: http://funes.uniandes.edu.co/754/1/lagestion.pdf

4. Loayza G. J. R.: Anexo 2, Criterios para la selección y elaboración y uso de materiales educativos. En Funciones de los materiales educativos en el proceso de enseñanza-aprendizaje en materiales de Enseñanza-Tecnología Educativa III, Facultad de Educación, Pontificia Universidad Católica del Perú, 1996. Recuperado en agosto 2014, disponible en http://www.bvsde.paho.org/cursoa_edusan/modulo4/ES-M04-L02-UCatolica.pdf.

5. European Commission, Digital Agenda for Europe: Survey of Schools: ICT in Education - Benchmarking Access, Use and Attitudes to Technology in Europe's Schools, Final Study Report, February 2013. Disponible en https://ec.europa.eu/digital-agenda/en/pillar-6-enhancing-digital-literacy-skills-andinclusion

6. Wiley, D. (Ed.): The Instructional use of Learning Objects. Agency for Instructional Technology (AIT) and the Association for Educational Communications and Technology (AECT), 2002. Disponible en: http://reusability.org/read/\#1

7. Ruiz-González, R.E.; J. Muñoz-Arteaga: F.J. Alvarez-Rodríguez.: Evaluación de Objetos de Aprendizaje a través del Aseguramiento de Competencias Educativas. Virtual Educa Brasil 2007. São Paulo, Brasil, 2007.

8. Barrit, C.; Alderman Jr., F. L.: Creating a Reusable Learning Objects Strategy. Leveraging Information and Learning in a Knowledge Economy. Pfeiffer (2004). Disponible

en: 
http://books.google.com.mx/books?hl=es\&lr=\&id=yl9HIQOTuEcC\&oi=fnd\&pg=PR1 1\&ots=nC9GgdIXPu\&sig=m9_2IYs_PqMDG49b1dx_gLxqBME\#v=onepage\&q\&f=fal se.

9. UAEMex (Universidad Autónoma del Estado de México). (s.f.). Estadística 2011, sobre Personal. Disponible en: http://www.uaemex.mx/planeacion/docs/AE2011/fscommand/AgEst_7.pdf

10. Rebollo, P. M.: Metodología docente y materiales didácticos para la enseñanza a distancia, 2007. Recuperado julio 2014, disponible en http://mrebollo.webs.upv.es/tic4edu/docs/materialesEaD.pdf

11. Godoy, R. C.: Educative uses of ICT, technological skills and academic performance of the Venezuelan university students (Barineses): A causal perspective. International Journal of Education and Development using Information and Communication Technology (IJEDICT), Vol. 2, Issue 4, pp. 28-43, 2006. Recuperado en agosto 2014, disponible en http://ijedict.dec.uwi.edu/viewissue.php?id=10

12. Blumenstock, J. E.: Size matters: word count as a measure of quality on wikipedia. Proc. of the 17th international conference on World Wide Web, pp. 1095-1096. Beijing, China, 2008.

13. Cechinel, C.; Sánchez-Alonso, S.; Sicilia, M.Á.; Velazquez-Amador, C.: Evaluating Models for Automated Quality Assessment of Learning Objects inside Repositories. 6th Latin American Conference on Learning Objects and Technology Enhanced Learning-LACLO, 2011.

14. Del Moral, Ma. E.; Villalustre L.: Didáctica universitaria en la era 2.0: competencias docentes en campus virtuales. Revista de Universidad y Sociedad del Conocimiento (RUSC), Vol. 9, No. 1, pp. 36-50 UoC, 2012. Recuperado en agosto 2014, disponible en http://rusc.uoc.edu/ojs/index.php/rusc/article/view/v9n1-moralvillalustre/v9n1-moral-villalustre.

15. Aguilar-Juárez, I; León-Chavez, M.A.: Metodología para el desarrollo de Objetos de Aprendizaje. En 3er. Congreso Nacional de Tecnologías en la Educación (CONTE), 24-26 septiembre, 2014.

16. Šed'ová, K.; Zounek, J.: Teachers Among modern Technologies. In ECER 2008. Recuperado en junio 2014, disponible en https://www.academia.edu/7886207/Teachers_Among_Modern_Technologies

17. Prendes, E. M. Paz; Gutiérrez, P. I.: Competencias tecnológicas del profesorado en las Universidades españolas. Revista de Educación, 361. Mayo-agosto 2013. Recuperado en agosto 2014, disponible en http://www.revistaeducacion.mec.es/doi/361_140.pdf 